\title{
Erratum to: Relationship between sleep apnea and thyroid function
}

\author{
Shoko Takeuchi • Takuro Kitamura • Toyoaki Ohbuchi • \\ Hiroki Koizumi • Risa Takahashi • Nobusuke Hohchi • \\ Hideaki Suzuki
}

Published online: 2 September 2014

(C) Springer-Verlag Berlin Heidelberg 2014

\section{Erratum to: Sleep Breath}

DOI 10.1007/s11325-014-0966-0

Unfortunately the values of FT4 are incorrectly displayed in Figure 1. This does not change the conclusions of this study. Please find the correct Figure 1 below.

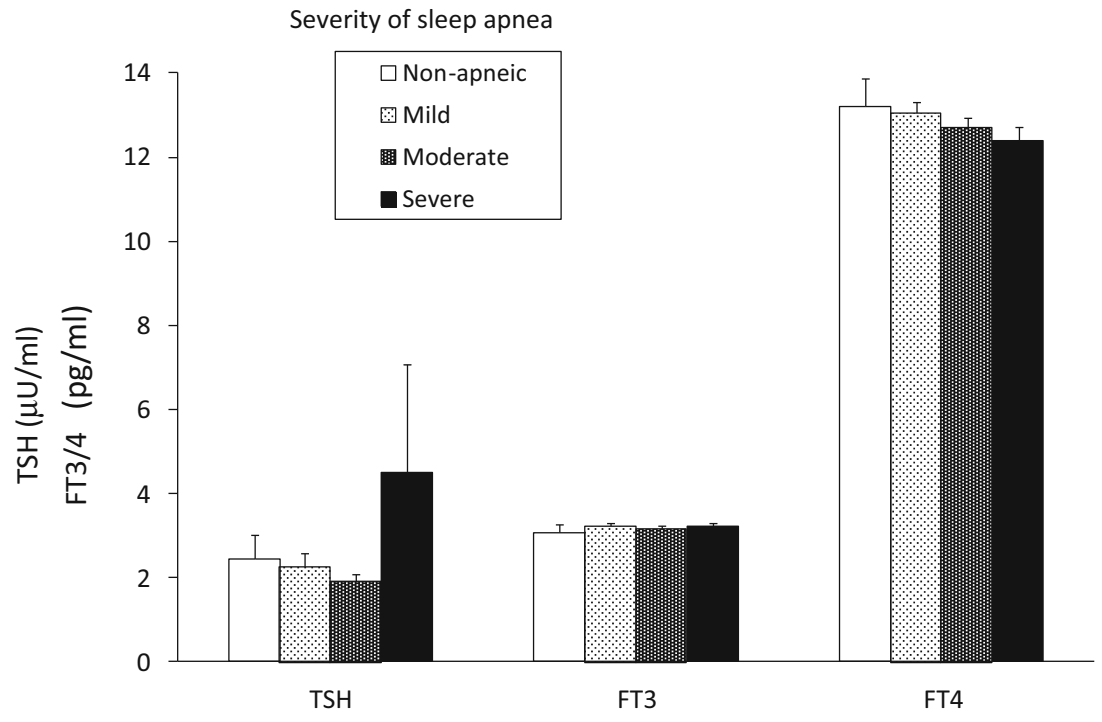

The online version of the original article can be found at http://dx.doi.org/ 10.1007/s11325-014-0966-0.

S. Takeuchi $\cdot$ T. Kitamura $\cdot$ T. Ohbuchi $\cdot$ H. Koizumi $\cdot$

R. Takahashi $\cdot$ N. Hohchi $\cdot$ H. Suzuki $(\bowtie)$

Department of Otorhinolaryngology-Head and Neck Surgery, School

of Medicine, University of Occupational and Environmental Health,

1-1 Iseigaoka, Yahatanishi-ku, Kitakyushu 807-8555, Japan

e-mail: suzuhyde@med.uoeh-u.ac.jp 